\title{
Historias de la aldea. Arqueología de las sociedades campesinas en el centro de la península ibérica (ss. VI-VIII d.n.e.)
}

\section{Tales from the village. Archaeology of peasant societies in the centre of the Iberian peninsula (6th-8th centuries)}

\author{
Carlos Tejerizo-García \\ carlosteje@gmail.com \\ Universidad del País Vasco/Euskal Herriko \\ Unibertsitatea, España
}

Recepción: 02 Febrero 2020

Aprobación: 14 Septiembre 2020

Publicación: 01 Marzo 2021

Cita sugerida: Tejerizo-García, C. (2021). Historias de la aldea. Arqueología de las sociedades campesinas en el centro de la península ibérica (ss. VI-VIII d.n.e.). Sociedades Precapitalistas, 11, e059. https://doi.org/10.24215/22505121e059
Resumen: El desarrollo de la arqueología en Europa occidental ha tenido como resultado el incremento exponencial de los datos sobre los contextos rurales en época altomedieval, lo que ha renovado por completo el análisis del campesinado en este período. Uno de los aspectos más desarrollados ha sido precisamente la arqueología de las aldeas, que está permitiendo obtener una información muy detallada sobre su génesis en la Alta Edad Media, sus características principales y el tipo de sociedades que vivían en ella. Esta información ha llevado a contrastar la idea de la vinculación causal entre la aldea medieval y el feudalismo, abriendo la oportunidad a análisis de tipo socio-económico mucho más complejos. En este trabajo presentaremos en primer lugar un análisis genealógico e historiográfico sobre la categoría de la aldea medieval para, en segundo lugar, construir una alternativa de conceptualización en términos antropológicos derivados de algunos análisis sobre el registro arqueológico de la meseta norte peninsular.

Palabras clave: Alta Edad Media, Hábitat rural, Arqueología, Campesinado, Meseta norte peninsular.

\begin{abstract}
The development of Archaeology in Western Europe had as a result the exponential growth of data on rural context in the Early Middle Ages, which has completely renewed the analysis on peasantry in this period. One of the aspects that developed the most has been, precisely, the archaeology of villages, which has come to a very detailed information on their genesis during early medieval times, their main characteristics and the type of societies which lived in them. This information came to revised the idea of the causal relation between the medieval village and feudalism, opening the possibility of analysing the socio-economic complexities of these societies. In this paper I will present, in the first place, a genealogic and historiographical analyses of the category of medieval village in order to, and in second place, build an alternative concept in anthropological terms, derived from some analyses on the archaeological record in the northern plateau of the Iberian peninsula.
\end{abstract}

Keywords: Early Middle Ages, Rural milieu, Archaeology, Peasantry, Peninsular northern plateau. 


\section{Introducción: entre el giro arqueológico y la revolución silenciosa $^{12}$}

En su libro The inheritance of Rome. A History of Europe from 400 to $1000 \mathrm{C}$. Wickham escribía sobre el campesinado de los siglos VI-VIII d.n.e. que: "we do not know much about most of them; peasant social practices were too far from the aristocratic and ecclesiastical interests of the great bulk of our written sources. For the most part, our evidence for peasants in the Pre-Carolingian West is archaeological" (2009, p. 204). En este párrafo, el historiador británico subraya, fundamentalmente, dos ideas. La primera es el reconocimiento de las grandes dificultades para abordar la cuestión del campesinado post-romano exclusivamente desde las fuentes escritas (Grey, 2011). Éstas no solo son escasas, sino que están fuertemente mediadas por los intereses de las clases explotadoras. El campesinado, como sigue Wickham, es visto desde fuera "by legislators and hagiographers, who have every moralistic reasons for mentioning them, and little sympathy for their values. But these hostile external observers were also in all our societies from social groups who were rather more powerful than the peasantry, and who were entirely prepared to coerce them if it was in their interests to do so" (2009, p. 204). El campesinado aparece en las fuentes escritas, entonces, fundamentalmente como un sujeto pasivo sobre el que ejercer una explotación y, como tal, las fuentes se ocupan de este grupo en términos instrumentales, esto es, si es necesario hacerlo ${ }^{3}$.

De forma complementaria, lo que se constata en esta cita es la importancia del papel jugado por el registro arqueológico para analizar el campesinado altomedieval. La incorporación del registro arqueológico en los estudios medievales peninsulares tiene un largo recorrido historiográfico que, solo recientemente, está siendo evaluado de forma compleja para la creación de nuevas narrativas sobre el período (Barceló, 1988b; Delogu, 2011; Martín Viso, 2016a). El desarrollo en Europa occidental de las leyes relativas a la gestión del patrimonio en los últimos treinta años -la ley de Patrimonio en España data de 1985- y el surgimiento de una rama específica de la arqueología cuyo objetivo era precisamente esta gestión tuvo la consecuencia, inesperada, de renovar por completo la historiografía altomedieval a través de la localización de cientos de contextos datados en este período. Este proceso ha sido bautizado como un "giro arqueológico" por autores como J. Escalona (Escalona Monge, 2009) o como una "revolución silenciosa" por otros como J.A. Quirós y B. Bengoetxea (Quirós Castillo y Bengoetxea Rementeria, 2010).

Las consecuencias empíricas, epistemológicas y teóricas de esta revolución han sido inmensas, y todavía se está evaluando su impacto (Quirós Castillo, 2018). Sin embargo, en mi opinión, dos son los campos sobre los que este cambio de paradigma ha tenido un mayor impacto. Por un lado, en la conceptualización del campesinado como grupo social con una agencia propia en la estructuración de las sociedades altomedievales (ver el trabajo de E. Daflon en este mismo dossier). Por otro, en la comprensión de los paisajes rurales; entendiendo paisaje como la suma histórica de las interacciones materiales entre la sociedad y el medio ambiente (Orejas Saco y Ruiz Del Árbol, 2013). En este trabajo nos ocuparemos 
principalmente de este segundo aspecto y nos centraremos en la cuestión de la aldea como espacio fundamental en el que tienen lugar las relaciones sociales de producción y reproducción de las sociedades campesinas altomedievales.

Una idea que estaba bien asentada en la historiografía es que la aldea medieval surgía en estrecha conexión con el progresivo desarrollo de las relaciones feudales (un trabajo de síntesis en la voz "aldea" en Bonnassie, 1983). La sujeción del campesinado a la tierra fue una de las claves del modo de producción feudal y la aldea fue una de sus materializaciones más visibles en el paisaje. Estas aldeas eran entendidas como núcleos más o menos concentrados de unidades domésticas con una cierta idea de territorialización y sometidas al poder de algún señor que extraía las rentas de las comunidades que vivían en ellas. Esta idea no está completamente errada, y efectivamente, no cabe duda de que uno de los grandes "éxitos" del feudalismo fue la sujeción del campesinado a la tierra, de la que producía aquella renta que sería posteriormente extraída (Fossier, 1990). Lo que no era del todo cierto era el proceso histórico de conformación de estas aldeas, aspecto que la arqueología está mostrando de forma reiterada en toda Europa occidental (Quirós Castillo, 2009).

En este trabajo abordaremos tres objetivos complementarios. Por un lado, realizar un análisis genealógico e historiográfico sobre la construcción de la categoría de aldea dentro de la historiografía al tomedieval -con especial referencia a las aportaciones desde la arqueología-, y, por otro, hacer una descripción detallada de algunas de las características principales de los núcleos habitacionales del mundo rural de la Alta Edad Media. De esta manera, este trabajo pretende ofrecer una caracterización propia de la aldea partiendo del registro arqueológico, útil para el análisis de las comunidades campesinas de la Alta Edad Media. Para ello, trabajaremos fundamentalmente sobre datos provenientes de la región central de la cuenca del río Duero, equivalente grosso modo a la meseta norte de la Península Ibérica durante el período entre los siglos VI y VIII d.n.e. complementados con algunos ejemplos de otros territorios, fundamentalmente Madrid y Cataluña.

\section{La aldea altomedieval: genealogía de un concepto.}

La aldea ha constituido un objeto central de estudio desde los inicios de la historia social y económica de la Alta Edad Media. En sus trabajos, autores como Marc Bloch, Georges Duby o Slicher Van Bath -por citar algunos de los más señeros- dedicaron mucho espacio a caracterizar la aldea como el espacio de encuadramiento principal del campesinado y de su acción social (Bloch, 2014; Duby, 1976; Slicher Van Bath, 1963). Sin embargo, dentro de esta línea de análisis, la aldea se constituía fundamentalmente como el marco en el que tenía lugar la extracción de rentas por parte de los señores. En otras palabras, su identidad en cuanto aldeas y en cuanto comunidades campesinas dependían no tanto de su estructuración interna como de su relación con los poderes señoriales. Dos importantes ideas emergen de esta línea. Por un lado, que la configuración de la aldea propiamente dicha se produce en el momento en el que esta extracción de rentas es efectiva y no antes. En consecuencia, antes de este proceso la aldea no estaba plenamente constituida y, por lo tanto, su proceso de génesis quedaba muy oscurecido y determinado por una "ilusión retrospectiva" impuesta 
desde una situación posterior (Watteaux, 2003). En segundo lugar, se hacía depender la emergencia de las comunidades campesinas medievales a la acción de las elites, y, en consecuencia, los procesos al interior de estas comunidades quedaban difuminados. Ni mucho menos se pretende decir que las cuestiones de la génesis de las aldeas o los procesos internos de las comunidades campesinas no interesaran. En gran medida, estas visiones estaban fuertemente determinadas por la escasez y mediación elitista de las fuentes, como ya comentamos antes.

Sin embargo la idea de que la aldea campesina medieval como tal se constituye como una consecuencia del proceso de feudalización se convirtió en un fuerte topos historiográfico. De esta manera, autores como R. Fossier o G. Bois fueron muy influyentes a la hora de vincular el nacimiento de la aldea con estos procesos de tipo señorial a partir de la conceptualización de la mutación feudal y de la nuclearización del poblamiento rural (Bois, 1989; Fossier, 1984, 1990). De esta manera, el poblamiento rural anterior al año mil quedaba caracterizado en términos de un poblamiento disperso e inestable de "protoaldeas" o "aldeas temporales". Como afirman J. Chapelot y R. Fossier:

\begin{abstract}
La tendance au regroupement de la population rurale dans des sites ruraux souvent construits, contrairement aux villae antiques, en matériaux périssables affecte 1 'ensemble de l'Europe même si le phénomène est moins marqué au sud qu'au nord. Il se caractérise par divers aspects très caractéristiques: $\mathrm{d}$ 'abord une certaine instabilité du peuplement (...) il semble que dans des zones bien connues, les hábitats ruraux de la période des $\mathrm{V}$-IX siècles aient souvent des durées $\mathrm{d}$ 'existence courtes, de l'ordre de deux ou trois siècles seulement (1985, p. 74).
\end{abstract}

Esta conceptualización de las "protoaldeas" fue muy influyente en la historiografía peninsular a través de figuras como J.A. García de Cortázar o P. Bonnassie, para quienes la aldea se consolidaría entre mediados del siglo IX y el siglo XI como un proceso de larga duración histórica (Bonnassie, 1983, p. 15; García De Cortázar, 1988, pp. 22-24). Si bien con matices y desde posicionamientos historiográficos distintos, esta es la idea que se proyectó en muchos de los trabajos -al menos en los más sobresalientes- sobre el poblamiento rural de la Primera Alta Edad Media durante la década de los años 90 y bien entrado el siglo XXI (Escalona Monge, 2002; Larrea, 1998; Martín Viso, 2000; Pastor Díaz De Garayo, 1996).

La arqueología altomedieval europea también asumió este paradigma desde sus inicios. En los pioneros trabajos realizados en Inglaterra, Francia y Alemania sobre los primeros contextos rurales altomedievales excavados en el primer tercio del siglo XX, estos se interpretaban como hábitats inestables y en cierta medida miserables en los que vivían las poblaciones germánicas post-romanas (Chapelot y Gentili, 2010; Guyan, 1952; Lethbridge and Tebbutt; citado en Hamerow, 2012, p. 8; Leeds, 1923). Sin embargo, el desarrollo de la arqueología medieval en Europa occidental pronto puso en entredicho estas ideas. Por el contrario, las excavaciones mostraban entornos rurales no solo complejos en términos constructivos, sociales y económicos, sino también muy estables en el tiempo y tremendamente resilientes con respecto al entorno natural en el que se insertaban (Catteddu, 2009; Hamerow, 2002, 2012; Nissen-Jaubert, 1995; Peytremann, 2003).

La mirada que sobre la aldea se desprendía de las fuentes escritas y la que emergía de los estudios arqueológicos cada vez era menos coherente. En 1995, 
la arqueóloga francesa E. Zadora-Río escribe un breve pero incisivo trabajo en el que subraya la dificultad de integrar la "aldea de los historiadores" con la "aldea de los arqueólogos" debido a la inconmensurabilidad de las categorías que se desprendían de ambas fuentes (Zadora-Rio, 1995). En un tono mucho más optimista e integrador se pronuncia J.A. Quirós Castillo, marcando una agenda de trabajo en el que la base social campesina sea el nexo de unión entre ambos registros o, mejor dicho, las narrativas construidas a partir de ambos registros (Quirós Castillo, 2007).

Así, en los últimos veinte años, tanto historiadores como arqueólogos -o, al menos, un sector de ambos colectivos- han hecho revisiones muy profundas sobre la conceptualización de la aldea altomedieval y de su papel en la configuración de los paisajes altomedievales. En este sentido, uno de los debates fundamentales se ha articulado en torno a la propia definición de la aldea en cuanto categoría útil para el análisis de las comunidades campesinas altomedievales. En la siguiente tabla recogemos algunas de las principales definiciones que algunos historiadores y arqueólogos han ofrecido sobre la aldea:

Tabla 2.1. Definiciones de una aldea, a partir de (Francovich, 2004; en Brogiolo y Chavarría Arnau, 2008; García De Cortázar, 1988; Martín Viso, 2000; Noël, 2010; Peytremann, 2003, p. 100)

\begin{tabular}{|c|c|}
\hline AUTOR & DEFINICIÓN \\
\hline K.S. Bader & $\begin{array}{l}\text { La Siedlungsgeschichte designa como aldea una unidad de hábitat más o menos concentrado, que } \\
\text { reagrupa cierto número de hogares y que, en tanto aldea, es reconocida como una comunidad de } \\
\text { vida y de actividades económicas... En sí, se constituye como "una colectividad, cerrada de } \\
\text { alguna manera sobre sí misma, de campesinos que viven de forma conjunta", que trabajan "los } \\
\text { unos al lado de los otros" y que tienen parte dentro de los bienes comunales. }\end{array}$ \\
\hline H. Jäger & $\begin{array}{l}\text { La aldea es un hábitat sedentario, de forma variable y basada en las actividades agrícolas. Consiste } \\
\text { en un grupo de explotaciones vecinas que utilizan espacios cultivados, y espacios económicos } \\
\text { complementarios y pueden disponer de establecimientos secundarios (por ejemplo para la } \\
\text { transhumancia). Las explotaciones se unen entre ellas a través de las instituciones comunales que } \\
\text { conciernen a la localidad y su territorio. }\end{array}$ \\
\hline R. Fossier & $\begin{array}{l}\text { La "village achevé" reagrupa el hábitat rural en torno a "puntos de cristalización" -la iglesia, el } \\
\text { cementerio, el castillo- y se caracteriza por la concentración de las casas en un sitio con un plan } \\
\text { organizado. } \\
\text { Hay que reservar el concepto a un grupo compacto de casas fijas, pero también a la presencia de } \\
\text { diversos nodos de agrupamiento donde los muertos jugaron un rol central, a una organización } \\
\text { coherente del terrazgo y sobre todo a la aparición de una toma de conciencia comunitaria sin la } \\
\text { cual no hay aldeanos sino simplemente habitantes }\end{array}$ \\
\hline J-M. Pesez & $\begin{array}{l}\text { La aldea es el producto original de las civilizaciones rurales del Occidente medieval... una } \\
\text { realidad, compleja, asociada a un edificio, un hábitat permanente fijado en el espacio, un terrazgo } \\
\text { agrícola, unos límites, y un grupo humano dotado de una personalidad moral que se desarrolla a } \\
\text { través de diversas instituciones y también de la parroquia y la comunidad rural. }\end{array}$ \\
\hline $\begin{array}{l}\text { M. Bourin y R. } \\
\text { Durand }\end{array}$ & $\begin{array}{l}\text { La aldea implica "la fijación duradera a un lugar preciso, una organización colectiva, más o menos } \\
\text { espontánea, del espacio habitado... con los edificios que refuerzan y simbolizan las solidaridades, } \\
\text { como la iglesia; con el castillo que es el polo de cristalización de algunas aldeas; con los espacios } \\
\text { comunes, el cementerio, la plaza u otras. La aldea es también la presencia de lugares de encuentro } \\
\text { donde se desarrolla una sociabilidad comunal, la forja, el molino...., la fuente. La aldea es } \\
\text { entonces, simplemente, un cierto encuadre monumental (cadre monumental) que desarrolla las } \\
\text { relaciones sociales de los aldeanos y la naturaleza de sus solidaridades. } \\
\text { Una aldea es un grupo de familias entre las que se han tejido medios (réseaux) de alianzas; es más, } \\
\text { bajo la "houlette" de su cura, una reunión de cristianos entre los que circulan intercambios de } \\
\text { piedad y "d'entraide". Pero es sobre todo un conjunto de sujetos del señorío. }\end{array}$ \\
\hline
\end{tabular}




\begin{tabular}{|c|c|}
\hline É. Zadora-Rio & $\begin{array}{l}\text { Para los arqueólogos, la aldea es sobre todo un grupo de casas más o menos significativo y } \\
\text { comporta una organización colectiva del espacio. Los criterios habituales utilizados comprenden la } \\
\text { existencia de un cierre en torno al espacio edificado, la presencia de una plaza central, el carácter } \\
\text { regular del plano, la presencia de zonas de actividades especializadas y, en resumen, la regularidad } \\
\text { de la morfología agraria. Los historiadores ponen en primer lugar por una parte la existencia de } \\
\text { una comunidad rural que tenga una personalidad jurídica y de un territorio agrario organizado, con } \\
\text { límites conocidos; por otra el agrupamiento duradero, en un mismo lugar de un cierto número de } \\
\text { funciones: religiosa, funeraria, defensiva, administrativa y económica. }\end{array}$ \\
\hline G. Duby & Aglomeración que se constituye a partir de una yuxtaposición de parcelas \\
\hline E. Salin & Una reunión de campesinos con intereses comunes \\
\hline A. Verhulst & $\begin{array}{l}\text { Un conjunto funcional que trasciende la simple yuxtaposición geográfica de algunas granjas y } \\
\text { casas, por muy poco numerosas que sean - un conjunto en el que la funcionalidad se manifiesta en } \\
\text { los elementos comunitarios como de zonas de agrupamiento para las bestias" }\end{array}$ \\
\hline $\begin{array}{l}\text { A.Nissen- } \\
\text { Jaubert }\end{array}$ & $\begin{array}{l}\text { Hábitat, reagrupado bajo el mismo nombre, asociado a un territorio donde los hombres (les } \\
\text { hommes) viven según una organización interna. Se hace posible entonces tener en cuenta por una } \\
\text { parte la continuidad del terreno (terroir) y por otra la existencia de una comunidad rural a pesar de } \\
\text { la movilidad del hábitat. }\end{array}$ \\
\hline R. Francovich & $\begin{array}{l}\text { Podemos considerar aldeas en el momento en que ofrecen residencia a un centenar de personas y } \\
\text { que constituyen un grupo social en condiciones de producir suficientes recursos, de expresar una } \\
\text { propia identidad y cohesión respecto a un territorio distinto al de otras comunidades }\end{array}$ \\
\hline $\begin{array}{l}\text { J.A. García de } \\
\text { Cortázar }\end{array}$ & $\begin{array}{l}\text { Un grupo humano asentado con carácter estable en un territorio explota, en núcleos familiares } \\
\text { conyugales, los espacios de huerto, viñedo y cereal, mientras aprovecha, con el conjunto de la } \\
\text { colectividad local, los de monte, bosque o aguas. }\end{array}$ \\
\hline I. Martín Viso & $\begin{array}{l}\text { Es un tipo de poblamiento concentrado, superior a la granja, donde habitan agrupaciones } \\
\text { superiores a la familia nuclear, pero con un número total bajo. Las actividades económicas que se } \\
\text { desarrollan en ella son básicamente referidas al sector primario, especialmente la agricultura, sin } \\
\text { que ello impida la presencia de algunos especialistas artesanos a tiempo parcial o total, pero } \\
\text { siempre como minoría. Todos estos elementos configuran una realidad física, pero la aldea es } \\
\text { también un agrupamiento de hombres en torno a un punto fijo del que depende la explotación de } \\
\text { un terruño delimitado, para lo que hace falta una toma de conciencia de intereses comunes y } \\
\text { duraderos que unan a sesos hombres. La aldea es, por lo tanto, una estructura distendida del } \\
\text { hábitat en la que los diversos caseríos o construcciones aisladas trabajan un territorio en el que se } \\
\text { distingue una cierta unidad, siendo precisa la formación de una conciencia aldeana propia con la } \\
\text { delimitación de un territorio y de los componentes de esa unidad que pueden disfrutar de aquél. }\end{array}$ \\
\hline
\end{tabular}

Como se puede observar de la lectura de estas categorizaciones de la aldea, hay algunos elementos que aparecen como más o menos comunes, caso de su carácter rural y/o campesino, la territorialidad o la existencia de nexos de unión social entre las distintas familias que conforman la aldea. Por el contrario, también existen elementos excluyentes e incluso contradictorios entre ellas, como es la diferente conceptualización de lo que es la estabilidad o la concentración, su tamaño, el papel jugado por los bienes comunales o la vinculación del campesinado con otros agentes sociales. Con el objetivo de superar estas contradicciones conceptuales una estrategia óptima podría la de proponer una definición heurística que nos permita distinguir entre lo que es y lo que no es una aldea en el registro arqueológico. En este sentido, creemos que la mejor opción es partir de una definición antropológica de las aldeas.

En el contexto de la antropología rural, quizá sea A.V. Chayanov el que primero y de forma más directa confrontó esta problemática. Así, este autor parte de la idea de la unidad doméstica como el lugar básico de encuadramiento del campesinado (Chayanov, 1966). Siguiendo esta lógica, la aldea se definiría de forma básica y como punto de partida como el agregado de unidades domésticas en torno a relaciones sociales de producción comunes dentro de una formación social dada. Unidad doméstica que se configuraría a partir de la agregación de los espacios domésticos (la casa) y los espacios de producción (parcelario, espacios de almacenamiento...). De esta manera, y siguiendo la propuesta de Alfonso Vigil-Escalera y de Juan Antonio Quirós (Vigil-Escalera, 2007; VigilEscalera y Quirós Castillo, 2013), una categorización heurística a priori muy útil 
para la identificación de una aldea en el registro arqueológico sería aquella que distinguiría la presencia de granjas o aldeas en función del número de unidades domésticas diferenciadas. Así, la presencia de una o dos unidades domésticas se correspondería con una granja y tres o más unidades domésticas con una aldea.

Con esta definición y categorización general, abordaremos en el próximo apartado la descripción detallada de las principales características que configurarían la arqueología de las aldeas en la cuenca del Duero entre los siglos V y VIII d.n.e.

\section{Arqueología de las aldeas en la cuenca del Duero}

Si bien la arqueología de las aldeas en la cuenca del Duero como tal data de los años 50 y 60 a partir de algunas excavaciones muy puntuales en contextos rurales altomedievales, hasta prácticamente el cambio de siglo apenas se conocía una veintena de yacimientos que permitieran profundizar arqueológicamente en esta cuestión (Tejerizo García, 2017). El impacto de las intervenciones de urgencia en la meseta norte de la península ibérica se desarrolló de forma distinta con respecto a otros territorios como Madrid, Cataluña o Galicia; si bien hubo un número muy significativo de intervenciones, muchas de estas se vincularon principalmente a la construcción de vías de ferrocarril, carreteras y pequeños polígonos industriales. El resultado fue la obtención de una masa de datos muy grande sobre contextos rurales altomedievales a partir de excavaciones lineales de gran recorrido, pero no hubo intervenciones en grandes extensiones como ocurrió, por ejemplo, en el sur de Madrid (Vigil-Escalera Guirado, 2018). Esto se suma a la situación común de la arqueología española, caracterizada por una dispersión de la masa empírica dentro de expedientes administrativos que, en pocas ocasiones, ven la luz (Tejerizo García y Quirós Castillo, 2018). De esta manera, sabemos de la excavación de un número muy alto de aldeas y granjas altomedievales en la cuenca del Duero, pero únicamente algunas de estas ofrecen información relevante para el propósito de este trabajo. Nos basaremos entonces en el registro obtenido de una treintena de casos que fueron objeto de un análisis crítico en una publicación reciente (FIGURA 1), y donde se pueden consultar estos datos (Tejerizo García, 2017). 


\section{Figura 1}

Principales aldeas y granjas altomedievales (ss. VI-VIII d.n.e.) en la meseta norte.

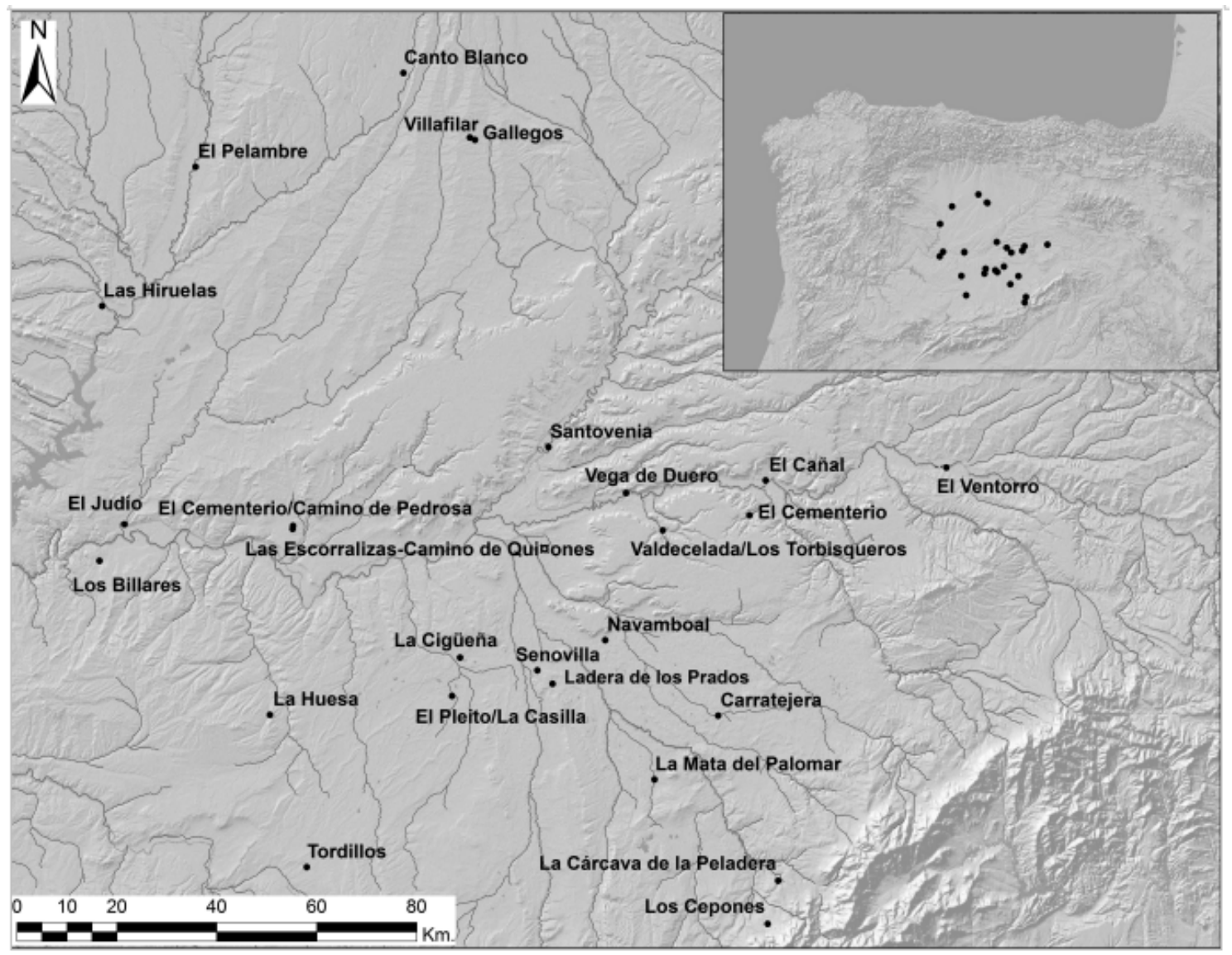

A partir de estos ejemplos, describiremos tres aspectos de las aldeas altomedievales en la cuenca del Duero: las unidades domésticas y su configuración dentro del espacio aldeano; la presencia (o ausencia) de entornos de creación de la identidad comunitaria; $y$, finalmente, algunos apuntes sobre la economía y la desigualdad social dentro de los contextos aldeanos.

\subsection{La conformación de las unidades domésticas}

Como ya comentamos, si partimos de una conceptualización antropológica de las sociedades campesinas, la unidad doméstica se convierte en el punto de partida analítico. Así, y gracias a los estudios sobre algunas de los contextos mejor excavados de la zona, como Mata del Palomar (Nieva, Segovia), Ladera de los Prados (Aguasal, Valladolid) o La Huesa (Cañizal, Zamora) podemos estimar que las aldeas de la cuenca del Duero se compondrían, aproximadamente, de unas 10-12 unidades domésticas ${ }^{4}$, lo que es coherente con otros estudios similares en otros territorios cercanos, como en Madrid o Cataluña (Roig Buxó, 2009, 2013; Vigil-Escalera, 2007; Vigil-Escalera y Strato, 2013, p. 167). Cada una de estas unidades domésticas estaría compuesta, a su vez -y como un tipoideal general-por una o dos estructuras principales con cimentación de piedra, entre tres y cinco estructuras auxiliares de fondo rehundido, dos o tres silos de almacenamiento asociados a la unidad doméstica y, quizá un pozo, que podía ser 
compartido por varias unidades domésticas. Veamos con un poco más de detalle cada uno de estos elementos.

Hasta hace relativamente poco se entendía que las poblaciones rurales postromanas vivían fundamentalmente en estructuras de materiales perecederos, tipo cabañas, construidas en madera y recubiertas con vegetales aislados con barro (López Quiroga, 2006). Esta idea provenía de una traslación a la península ibérica de aquellas construcciones que se documentaban en Centroeuropa y vinculadas a las sociedades bárbaras más allá de las fronteras del imperio (Donat, 1980). Sin embargo, las múltiples excavaciones llevadas a cabo en países como Francia, Italia o España han demostrado que las principales viviendas de los contextos aldeanos se construían mediante cimentaciones de piedra sobre las que se elevaban paredes de adobe o tapial (Vigil-Escalera, 2003). Es más, la simplificación y territorialización de las tecnologías vinculadas a la construcción de los espacios domésticos en el mundo rural generó patrones regionales dependiendo de las tradiciones locales y la geología del terreno (Azkarate Garai-Olaun y Quirós Castillo, 2001; Tejerizo García, 2012).

Estas estructuras principales vendrían acompañadas de diversas estructuras auxiliares en la forma de lo que se ha llamado "estructuras de fondo rehundido", estructuras construidas en materiales perecederos -ahora sí, cabañascaracterizadas por la presencia de un nivel de suelo excavado en la tierra. Como demostró J. Tipper en su detallado análisis de estas estructuras, las funciones que cubrían dentro de las unidades domésticas eran muy variadas, incluyendo almacenes, hogares, telares, almacenes de grano, zonas de cocción de pan, etc. (Tipper, 2004, p. 160). Análisis geoarqueológicos realizados sobre algunas de ellas han demostrado que podían ser usadas para la fermentación de cerveza y de queso así como para las labores textiles más complejas, como el tintado de la ropa (Milek, 2012).

Una de las estructuras más interesantes del registro arqueológico vinculada a las aldeas altomedievales es el silo de almacenamiento (Vigil-Escalera, Bianchi, y Quirós Castillo, 2013) (FIGURA 2). Esta estructura, también excavada en la tierra, supone la aparición de una forma radicalmente distinta de gestión de parte de la producción (sobre todo la cerealística) y su almacenamiento con respecto al mundo imperial romano, basado en los grandes horrea para la centralización de la producción. Hasta el momento, no se han localizado este tipo de silos asociados a contextos de los siglos II-IV d.n.e. Y es que se trata efectivamente de un cambio sustancial detectado a partir de la quinta centuria que nos pone en relación con transformaciones profundas en la estructura económica, tanto en las relaciones sociales de producción como en las propias fuerzas productivas. Como ya advierte A. Vigil-Escalera: "son las formas de gestión de los excedentes en un determinado contexto social las que a veces cambian, y no el empleo de una técnica u otra, de una estructura especifica u otra" (Vigil-Escalera, 2013b, p. 142). En prácticamente todas las unidades domésticas excavadas se han localizado silos de almacenamiento asociados, y que podemos vincular al almacenamiento de la producción doméstica, ya sea como alimento, como reserva para la siguiente cosecha o como renta (Wolf, 1966). Los cálculos efectuados sobre su capacidad muestran que estos silos almacenarían una cantidad aproximada equivalente a 1500-2500 litros, es decir, el equivalente aproximado al consumo de una unidad doméstica en un año (Vigil-Escalera, 2013b). 


\section{Figura 2}

Silos localizados en el yacimiento de Ladera de los Prados (Vigil-Escalera y STRATO, 2013)

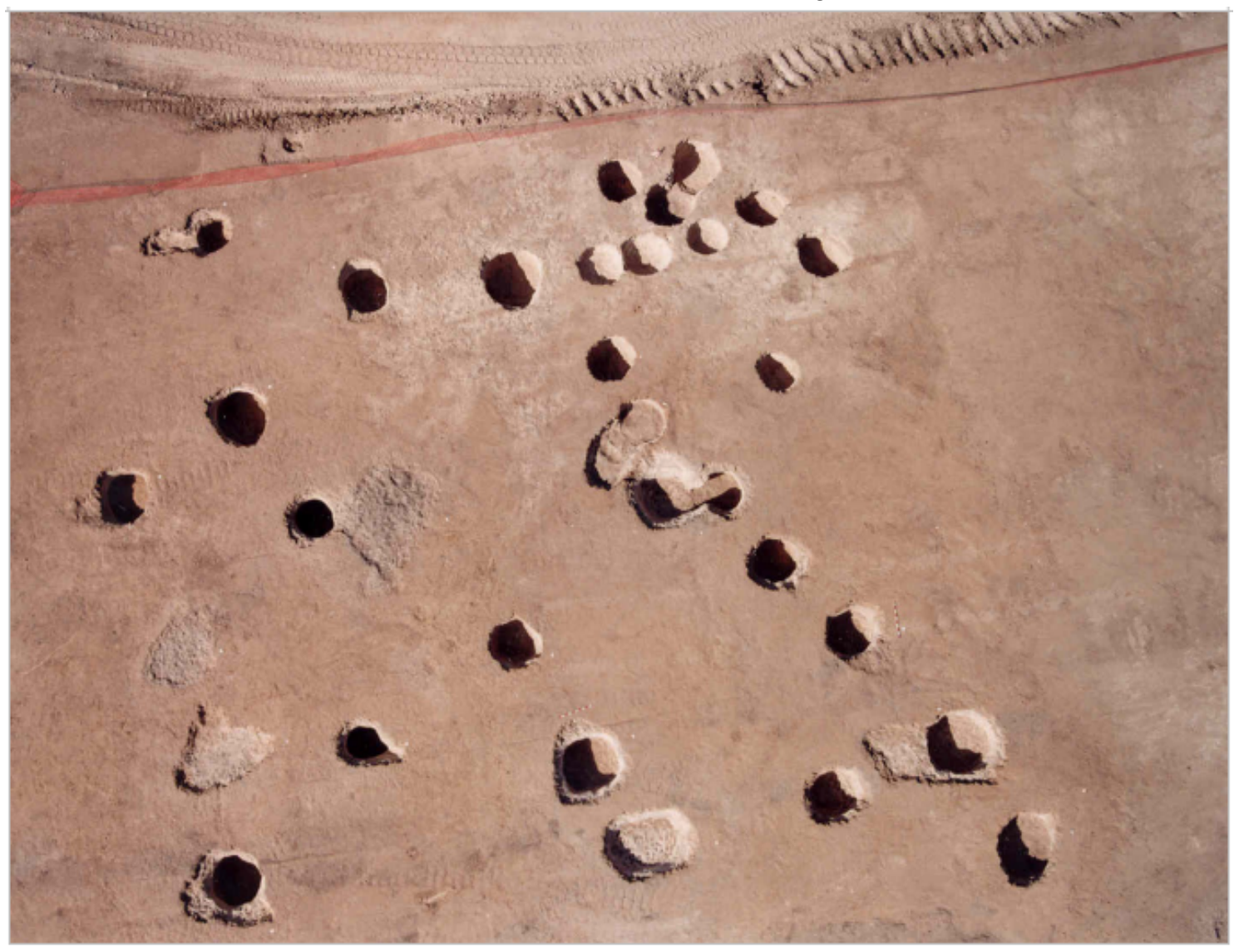

Por último, cabría hacer mención al parcelario de estas aldeas. Uno de los grandes avances en la arqueología altomedieval de los últimos años ha sido el impulso a los análisis en relación a los espacios productivos de las comunidades campesinas, lo que se ha denominado como "arqueología agraria" (Fernández Mier, et al., 2014; Kirchner, 2010). Dentro de esta arqueología agraria, un elemento de gran interés ha sido el reconocimiento arqueológico del parcelario vinculado a las unidades domésticas altomedievales. Por ejemplo, algunos interesantes estudios en Francia han demostrado la conservación de parte del parcelario agrario desde época prehistórica hasta la Alta Edad Media (Catteddu, 2012), lo que pondría en contacto la materialidad de sociedades de tipo campesino en la larga duración histórica. El yacimiento donde mejor ha sido reconocido este sistema de parcelario sería en Gozquez, se trataría de una organización del asentamiento caracterizado por la fijación en el espacio de las unidades domésticas, que comprenderían una extensión de terreno propio en la que se desarrollarían todas las tareas de las unidades domésticas así como la construcción y reconstrucción de las estructuras domésticas, que "no rebasan esos límites y dentro de cada parcela "edificada" se encuentra su historia al completo" (Vigil-Escalera y Quirós Castillo, 2013, p. 369). En el caso de la cuenca del Duero, si bien más limitado por el tipo de excavaciones llevadas a cabo que dificultan la detección de estos patrones, este tipo de organización interna ha sido reconocido en sitios como La Mata del Palomar, Navamboal (Íscar, Navamboal) o Canto Blanco (Calzada del Coto, León). 


\subsection{Identidades comunitarias}

Como hemos visto, el grueso de las aldeas altomedievales -o, al menos, de aquellas sobre las que tenemos más información- se conformarían a través de la yuxtaposición de distintas unidades domésticas con terrenos particulares que se desplegarían en amplias extensiones 5 . De alguna manera, la idea que se desprende del análisis de la organización espacial de estas aldeas es la de una autonomía de las unidades domésticas y la ausencia de prácticas e identidades comunitarias. Por el contrario, existen diversos indicadores arqueológicos que muestran claramente su existencia y que mostrarían la complejidad sociopolítica de estas comunidades.

El mejor indicador arqueológico es, sin duda, la presencia de los cementerios comunitarios. Se trataría de extensos cementerios, organizados normalmente en líneas -de ahí que se conozcan como los Reihengräberfelder o cementerios en líneas (Jepure, 2012)- que pueden llegar a las 600-700 tumbas como en el caso de Duratón, Madrona o Castiltierra ${ }^{6}$ (los tres ubicados en la provincia de Segovia), y que se localizarían a una cierta distancia de las unidades domésticas, a las que darían servicio (FIGURA 3). En el caso de la aldea de Gózquez (San Martín de la Vega, Madrid) se mostraría como el cementerio se articularía como un punto central entre dos barrios domésticos. La presencia en algunas de las tumbas de estos cementerios de fastuosos elementos de decoración personal ha llevado a que, tradicionalmente, hayan sido interpretados bajo el paraguas teórico de la Historia-Cultural como la expresión arqueológica de la llegada de los visigodos a la península ibérica (Barroso Cabrera, 2018). Sin embargo, nuevas aproximaciones han relativizado esta conexión y apuntan a la naturaleza campesina de sus enterrados (Quirós Castillo y Castellanos, 2015). 


\section{Figura 3}

Planta del cementerio de Madrona (Jepure, 2012)

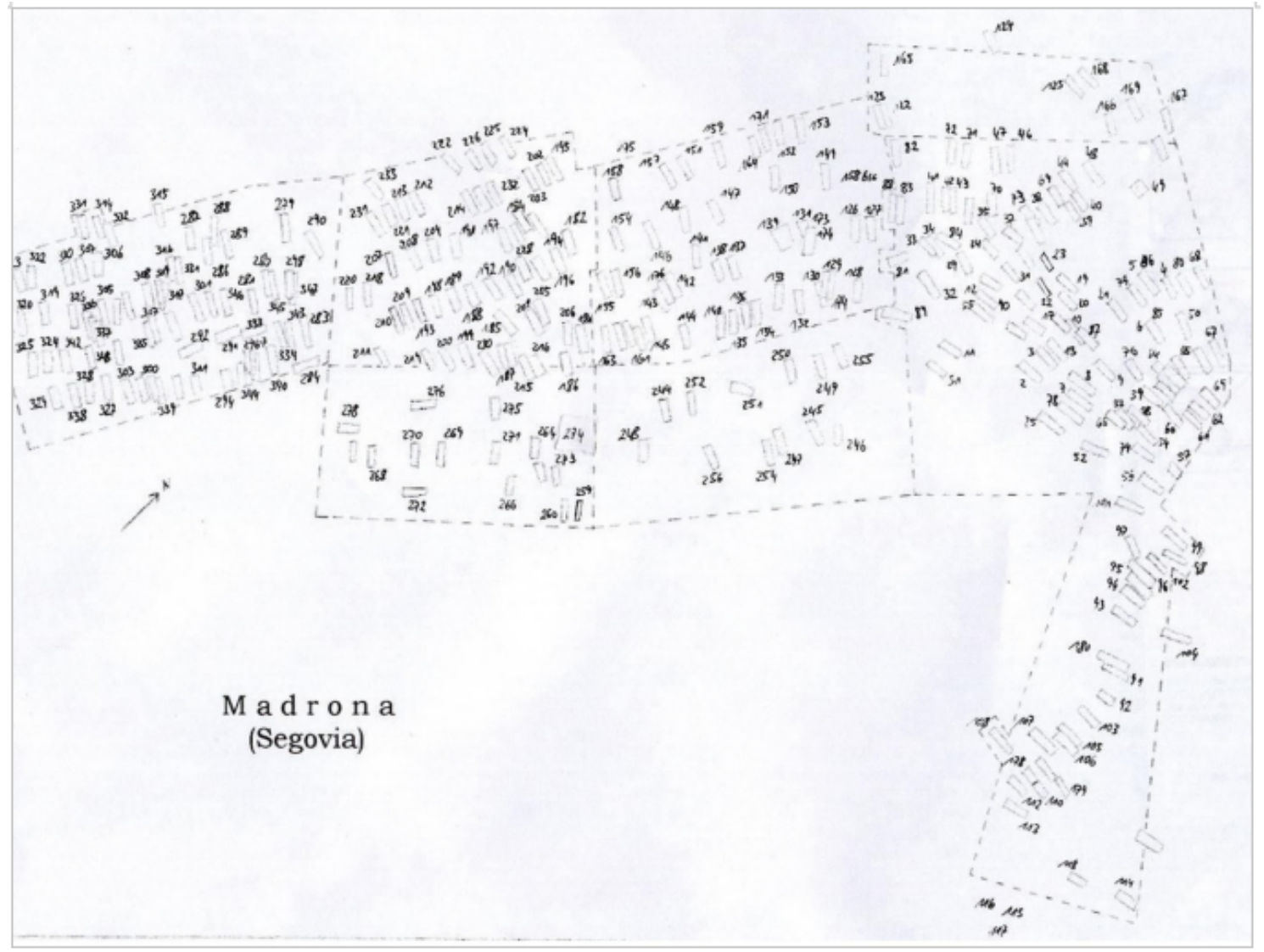

La presencia de estos cementerios comunitarios en estrecha conexión con las aldeas altomedievales subrayan su importancia como espacios performativos para la construcción de identidades comunitarias locales en el mundo rural (Halsall, 1992). La muerte en el mundo rural no es solo un evento traumático sino también un momento en el que las unidades domésticas refuerzan sus relaciones con la comunidad a través de las prácticas rituales. Prácticas que incluirían la exhibición del cuerpo, el propio funeral o incluso la celebración de fiestas (Parker Pearson, 1993). Todas estas prácticas implican la creación social de similitudes y diferencias dentro de una comunidad política, materializada mediante, por ejemplo, la exhibición y amortización de elementos de adorno personal de gran capital social, económico y simbólico (Tejerizo García, 2015). Un análisis similar se ha sugerido para interpretar parte de los cementerios en roca típico de las zonas de sierra en el suroeste de la cuenca del Duero (Martín Viso, 2016b).

Si bien los cementerios comunitarios podrían considerarse los elementos materiales que mejor evidencian estas prácticas comunitarias de creación de identidades aldeanas, otros podrían apuntarse, como sería la presencia de pozos usados por varias unidades domésticas dentro de las aldeas, como podría sugerirse para casos como La Mata del Palomar, o la documentación de estructuras comunitarias para la elaboración del pan, en este caso sugerido para la aldea catalana de Can Gambús-1 (Roig Buxó, 2009). Tareas que implicarían el establecimiento de relaciones sociales entre las distintas unidades domésticas dentro del territorio propio de la aldea. 
Otras evidencias de creación de identidades comunitarias intra-aldeanas podrían ser más indirectas arqueológicamente pero efectivamente funcionales en el contexto altomedieval. Algunas de estas evidencias aparecen en algunos interesantes textos como el de la Vita Sancti Aemiliani, un texto del siglo VII d.n.e. que nos ofrece una biografía de este santo (Castellanos, 1995). En algunos pasajes el autor menciona indirectamente la presencia de reuniones en las comunidades aldeanas, por ejemplo, durante la construcción de las casas, o celebraciones comunitarias con vino ${ }^{7}$. Teniendo en cuenta la complejidad estructural derivada del análisis de la sección anterior, se podría sugerir la idea de que la construcción y re-construcción de las unidades domésticas dentro de las aldeas podría convertirse en prácticas comunitarias que reforzarían la identidad intra-aldeana, al igual que las festividades que jalonarían el calendario agrario o los rituales religiosos, que crearían una idea de lo "público" que reforzaría estas identidades (Addison, 2020). Arqueológicamente tenemos constancia de estas fases de construcción y re-construcción de las estructuras dentro de las unidades domésticas en ciclos posiblemente generacionales (Tejerizo García, 2012), lo que invita a pensar en momentos, no solo de reforzamiento de las relaciones sociales al interior de la unidad doméstica sino también de esta en relación con el resto de la comunidad.

De igual forma se podría sugerir que la constatación documental de eventos políticos como los conventus publici vicinorum, asambleas de vecinos rurales que aparecen en los textos legales de los siglos VI y VII d.n.e. (Daflon, 2015) tendrían su correlato material en los escasos -y aún por estudiar- lugares de asamblea altomedievales en el centro peninsular (Vigil-Escalera Guirado, 2019). En el caso de la cuenca del Duero, es especialmente interesante el sitio de Domingo García (Segovia) (FIGURA 4). Este yacimiento, localizado en un pequeño montículo con una posición preeminente en el entorno, contiene una iglesia románica -en la que no se descarta la presencia de fases anterior-con un cementerio en roca de una docena de tumbas y rodeado de un significativo conjunto de grabados que incluyen algunos de época medieval (Pecci Tenrero y Ripoll López, 2011). Las prospecciones realizadas en su entorno parecen señalar, como hipótesis, que este sitio podría funcionar como un lugar de articulación del conjunto de aldeas altomedievales localizadas en su entorno (Tejerizo García, Carvajal Castro, Marín Suárez, Martínez Álvarez, y Mansilla Hortigüela, 2015).

\section{Figura 4}

El yacimiento de Domingo García. A la derecha, un panel con grabados

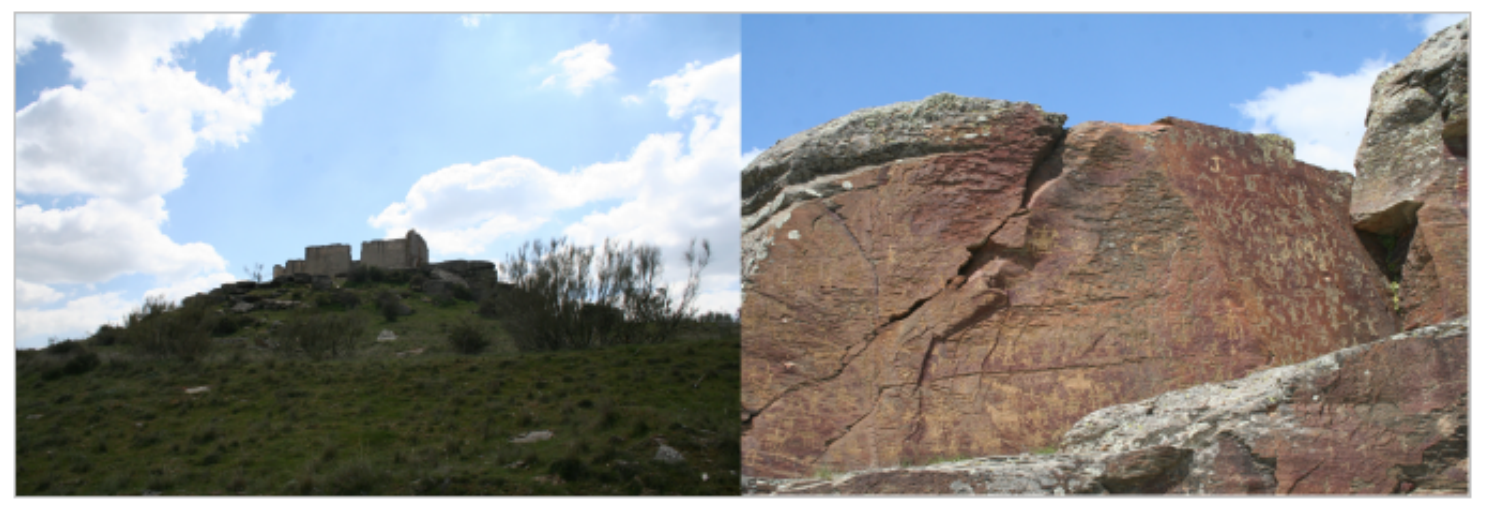




\subsection{Economia y desigualdad social en las aldeas altomedievales}

Dentro del esquema conceptual derivado de las "protoaldeas" comentadas al inicio, se entendía que las sociedades rurales previas al feudalismo eran relativamente igualitarias o, al menos, que no existían unos mecanismos institucionalizados de desigualdad social. Algunas líneas de trabajo, como la marcada por P. Bonnassie, ponían en entredicho esta aseveración, afirmando la continuidad y fortaleza del esclavismo más allá de la desintegración del imperio romano (Bonnassie, 1988). En lo que tiene que ver con su economía, en general, se preservaba la idea de sociedades especialmente expuestas al contexto ambiental y climático, con una escasa capacidad de adaptación (García Moreno, 1986).

La arqueología está permitiendo matizar y profundizar en la cuestión de las formas económicas y sociales dentro de las comunidades aldeanas altomedievales. Si bien los análisis densos son todavía escasos, y además todos ellos apuntan a dinámicas territoriales y locales muy dispares, sí que se puede ofrecer una cierta idea sobre las formas de vida y la economía de estas comunidades. En líneas generales, nos encontramos con sociedades con un desarrollo ciertamente escaso de las fuerzas productivas, con herramientas y formas productivas muy localizadas y vinculadas a las específicas condiciones geográficas de cada territorio (Wickham, 2008). Formas productivas en las que a juzgar por el registro arqueológico derivado de las aldeas altomedievales en el centro peninsular -sobre todo, el registro bioarqueológico basado en el estudio de los restos orgánicos de huesos, semillas o pólenes-, predominaría la integración entre una ganadería fundamentalmente estante y una agricultura diversificada (Vigil-Escalera, et al., 2014). Esto no es contradictorio con la presencia de algunos registros que mostrarían indicios de una cierta especialización dentro de la diversificación, basada fundamentalmente en las potencialidades económicas microrregionales y la adaptación de estas sociedades al medio ambiente haciendo un uso intensivo de los recursos locales. Sin embargo, la norma general muestra la diversificación como estrategia económica, dirigida a combatir la variabilidad y los factores de estrés y riesgo a los que se ven sometidas estructuralmente las economías de tipo campesino, como son la climatología, las rapiñas o las epidemias, y que permitiría no solo producir lo suficiente para la supervivencia sino también para el potencial pago de rentas a agentes externos (Halstead y O'shea, 1989). En otras palabras, el registro arqueológico muestra de forma cada vez más clara la capacidad de resiliencia y de adaptación al medio de las sociedades campesinas altomedievales.

Del mismo modo, el análisis del registro arqueológico proveniente de los contextos rurales altomedievales está permitiendo matizar la idea de que nos encontramos ante sociedades igualitarias. Un rasgo evidente de la presencia de desigualdades internas dentro de las aldeas del centro peninsular proviene precisamente de los cementerios comunitarios anteriormente comentados. La disposición de ajuares de un capital social, económico y simbólico tan diferenciado mostraría la presencia de individuos o familias con una posición social particularizada con respecto al resto de la comunidad (Tejerizo García, 2015). Por otro lado, el hallazgo de un número no menor de enterramientos dentro de los silos de almacenamiento (FIGURA 5), con un tratamiento claramente excluyente de los rituales normalizados de la comunidad -enterrados, en muchas ocasiones, junto a animales y desperdicios- ha permitido a autores 
como J. Roig o A. Vigil-Escalera a identificar a estos enterrados con dependientes domésticos o incluso con esclavos (Roig Buxó y Coll Conesa, 2011; VigilEscalera, 2013a).

\section{Figura 5}

Enterramiento en silo en el yacimiento de La Mata del Palomar (Vigil-Escalera y Strato, 2013)

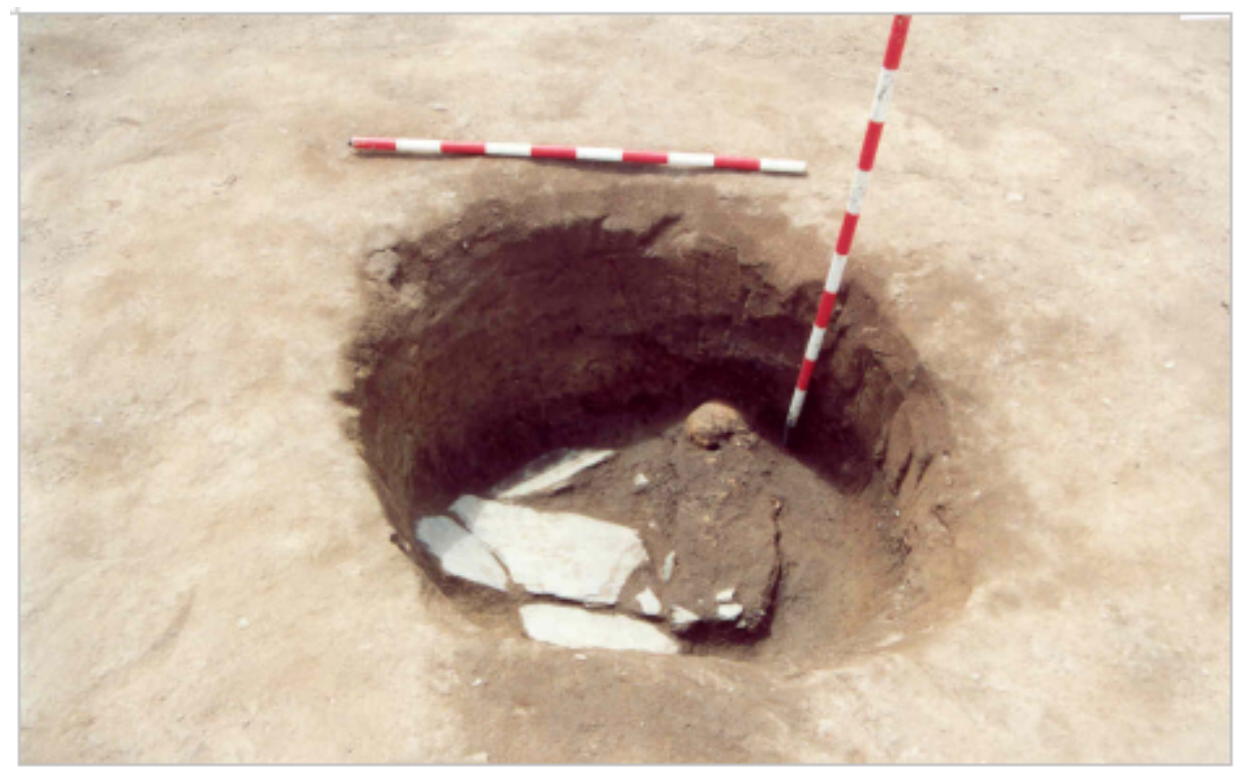

\section{Conclusiones: por una antropología de la aldea campesina altomedieval}

En este trabajo se han descrito algunas de las principales características de las aldeas rurales de época altomedieval del centro peninsular a partir de las últimas tendencias dentro del análisis del registro arqueológico. Una arqueología que está viviendo un momento de gran renovación a partir de, entre otras cuestiones, una definitiva inserción dentro de la medievalística, como ya proponía en su día M. Barceló (Barceló, 1988a). Una de las aportaciones más interesantes de esta nueva arqueología medieval ha sido la de profundizar en los hábitats rurales de época altomedieval, un aspecto muy oscurecido por el análisis de las fuentes escritas, muy mediadas por las agencias de las élites.

En este sentido, la arqueología permite reconsiderar conceptualmente el significado y alcance de la aldea como el principal hábitat rural de este período, el "mundo campesino" por excelencia. Partíamos en este trabajo de una caracterización heurística de la aldea como herramienta de identificación arqueológica. Una vez descritos sus principales componentes y características, podemos profundizar en una definición más antropológica de la aldea medieval. Así, y a partir del anterior análisis, podríamos identificar la aldea a partir de los siguientes elementos:

1. agregación y agrupamiento de varias unidades domésticas próximas geográficamente, si bien no implica su nuclearización extrema.

2. presencia de espacios económicos y de socialización comunes. 
3. una territorialidad definida, al menos, de facto y subjetivamente, por parte de la comunidad.

4. una identidad común compartida por las unidades domésticas que conformarían la aldea y que señalarían a la aldea como una "unidad social" (Pastor Díaz De Garayo, 1996)

Así, a partir de esta categorización antropológica, es posible hacer una distinción en términos abstractos de una aldea pre-feudal y una aldea feudal, cuya diferencia sería la relación específica que estas comunidades establecieran con el mundo circundante (Wolf, 1966). Así, y en términos generales, las aldeas pre-feudales se caracterizarían por unos niveles menos desarrollados de institucionalización de las desigualdades y de extracción del excedente, que dejarían un alto grado de autonomía a las unidades domésticas. Un esquema que encajaría bien con el llamado "modo de producción campesino" delineado por C. Wickham y que, a su vez, se presenta como una herramienta heurística muy apropiada para interpretar el registro arqueológico de las aldeas altomedievales al igual que los textos escritos (Da Graca, 2015; Wickham, 2005). Por su parte, la institucionalización y normalización de las relaciones feudales modificarían profundamente los paisajes campesinos, entre otros factores, por las necesidades de control de la extracción del excedente por parte de los señores feudales y del Estado, lo que se ha explicado historiográficamente mediante marcos conceptuales como son los procesos de nuclearización, parroquialización o de incastellamento, por mencionar aquellos modelos más elaborados (Quirós Castillo, 2007).

Sin embargo, hay que ser precavido de hacer categorizaciones muy estrictas o generalizaciones abusivas, como bien argumenta J. Banaji en torno a la crítica del "modo de producción campesino" (Banaji, 2010, p. 215 y ss.). En palabras de A. Nissen-Jaubert, "Cependant, à vouloir définir le village de manière trop stricte, on risque ensuite de négliger les indices de concertation commune ou de planification dans l'organisation du terroir et des activités agricoles" (NissenJaubert, 2006, p. 156). Definir y caracterizar de forma precisa lo que es y no es una aldea es el elemento fundamental que permite fijar, por ejemplo, el propio "nacimiento de la aldea" en un momento histórico determinado o su diferenciación y caracterización particular en períodos distintos. Como bien apunta C. Wickham, la cuestión de si antes del siglo IX se puede hablar de "aldea" es en gran medida una cuestión conceptual y del "tipo-ideal" que se aplique al análisis histórico (Wickham, 2010).

Si bien queda mucho por investigar y analizar, la arqueología de las aldeas altomedievales de la última década está abriendo enormes posibilidades para profundizar en la enorme complejidad que caracterizó a estos entornos en un período que, hasta muy recientemente, era entendido como oscuro.

\section{Referencias}

Addison, D. (2020). Property and 'publicness': bishops and lay-founded churches in post-Roman Hispania. Early Medieval Europe, 28(2), 175-196.

Azkarate Garai-Olaun, A., y Quirós Castillo, J. A. (2001). Arquitectura doméstica altomedieval en la Península Ibérica. Reflexiones a partir de las excavaciones 
arqueológicas de la Catedral de Santa María de Vitoria-Gasteiz, País Vasco. Archeologia Medievale(XXVIII), 25-60.

Banaji, J. (2010). Theory as History: Essays on Modes of Production and Exploitation. Leiden: Brill.

Barceló, M. (1988a). Arqueología Medieval. En las afueras del "medievalismo". Barcelona: Crítica.

Barceló, M. (1988b). Prólogo. En M. Barceló (Ed.), Arqueología medieval en las afueras del "medievalismo" (pp. 9-17). Barcelona: Crítica.

Barroso Cabrera, R. (2018). Etnicidad vs. Aculturación. Las necrópolis castellanas de los siglos V-VI d.C.y el asentamiento visigodo en la Peninsula Ibérica: una mirada desde la meseta sur. Oxford: Archaeopress.

Bloch, M. (2014). Feudal society. London: Routledge.

Bois, G. (1989). La mutation de l'An mil: Lournard, village mâconnais, de l'Antiquité au féodalisme. Paris: Fayard.

Bonnassie, P. (1983). Vocabulario básico de la historia medieval. Barcelona: Crítica.

Bonnassie, P. (1988). Cataluña mil años atrás (siglos X-XI). Barcelona: Edicions 62.

Brogiolo, G. P., y Chavarría Arnau, A. (2008). El final de las villas y las transformaciones del territorio rural en el occidente (siglos V-VIII). En C. Fernández Ochoa, V. García Entero y F. Gil Sendino (Eds.), Villas tardorromanas en Hispania (pp. 193-214). Gijón: Trea.

Castellanos, S. (1995). Problemas metodológicos en la investigación de la ocupación del territorio durante la Antigüedad Tardía: el caso del Alto Ebro y la aportación de la Vita Sancti Aemiliani. Brocar(19), 27-48.

Catteddu, I. (2009). Archéologie médiévale en France. Paris: La Découverte.

Catteddu, I. (2012). Archéologie des sociétés rurales altomédiévales dans la moitié nord de la France: modes d'habitats, gestion de l'espace, pratiques agropastorales et milieux (études de cas d'archéologie préventive). Thèse doctoral d'Archéologie inedite. Université de Paris I Panthéon-Sorbonne.

Chapelot, J., y Fossier, R. (1985). Le village et la maison au Moyen Age. London: Batsford.

Chapelot, J., y Gentili, F. (2010). Trente ans d'Archéologie médiévale en France. En J. Chapelot (Ed.), Trente ans d'archéologie médiévale en France. Un bilan pour un avenir (pp. 3-24). Caen: CRAHM.

Chayanov, A. V. (1966). The theory of peasant economy. Manchester: Manchester University Press.

Da Graca, L. (2015). Peasant mode of production and the evolution of clientelar relations. En L. Da Graca y A. Zingarelli (Eds.), Studies on pre-capitalist modes of production (pp. 158-203). Chicago: Haymarket books.

Daflon, E. C. (2015). Tumultos e clamores: assembleias rurais e resistência camponesa na Hispânia Visigoda (Séculos VI-VIII). Brathair, 15(2), 132-167.

Delogu, P. (2011). Storia e Archeologia, sorellegelose Riccardo Francovich e i granditemi del dibattito europeo: archeologia, storia, tutela, valorizzazione e innovazione (pp. 59-64). Firenze.

Donat, P. (1980). Haus, Hof und Dorf. Berlin: Akademie Verlag.

Duby, G. (1976). Guerreros y campesinos. Desarrollo inicial de la economía europea (500-1200). Madrid: Siglo XXI.

Escalona Monge, J. (2002). Sociedad y territorio en la Alta Edad Media Castellana: La Formación del Alfoz de Lara. Oxford: British Archaeological Reports. 
Escalona Monge, J. (2009). The early Castilian peasantry: an archaeological turn?. Journal of Medieval Iberian Studies, 1(2), 119-145.

Fabián, J., Santonja, M., Fernández, A., y Benet, N. (1985). Los poblados hispanovisigodos de Cañal, Pelayos (Salamanca) Congreso de Arqueología Medieval Española (Vol. I, pp. 187-201). Huesca: Diputación General de Aragón.

Fernández Mier, M., Fernández Fernández, J., Alonso González, P., López Sáez, J. A., Pérez Díaz, S., y Hernández Beloqui, B. (2014). The investigation of currently inhabited villages of medieval origin: agrarian archaeology in Asturias (Spain). Quaternary International, 346 (pp. 41-55).

Fossier, R. (1984). La infancia de Europa. Aspectos económicos y sociales. Barcelona: Labor.

Fossier, R. (1990). La naissance du village. En R. Delort (Ed.), La France de l'an Mil (pp. 162-168). Paris: Éditions du seuil.

García De Cortázar, J. Á. (1988). La sociedad rural en la España medieval. Madrid: Siglo veintiuno.

García Moreno, L. A. (1986). El campesino hispanovisigodo entre bajos rendimientos y catástrofes naturales. Su incidencia demográfica Antigüedad y Cristianismo. Los visigodos: Historia y civilización (Vol. III, pp. 171-187): Universidad de Murcia.

Grey, C. (2011). Constructing communities in the Late Roman Countryside. Cambridge: Cambridge University Press.

Guyan, W. U. (1952). Einige Karten zur Verbreitung des Grubenhauses in Mitteleuropa im ersten nachchristliechen Jahrtausend. Jabrbuch der Schweizerischen Gesellschaft für Urgeschichte (42), 174-197.

Halsall, G. (1992). The origins of the Reihengräberzivilisation: forty years on. En J. Drinkwater y H. Elton (Eds.), Fifth-century Gaul, a crisis of identity? (pp. 196-207). Cambridge: Cambridge University Press.

Halstead, P., y O'shea, J. (1989). Introduction: cultural responses to risk and uncertainty. En P. Halstead y J. O'shea (Eds.), Bad year economics. Cultural responses to risk and uncertainty (pp. 1-7). Cambridge: Cambridge University Press.

Hamerow, H. (2002). Early medieval settlements: The Archaeology of Rural Communities in North-West Europe 400-900. Oxford: Oxford University Press.

Hamerow, H. (2012). Rural settlements and society in Anglo-Saxon England. Oxford: Oxford University Press.

Jepure, A. (2012). Das westgotenzeitliche Gräberfeld von Madrona (Segovia, Spanien). Würzburg: Universität Würzburg.

Kirchner, H. (2010). Por una arqueología agraria: perspectivas de investigación sobre espacios de cultivo en las sociedades medievales hispánicas. Oxford: Archaeopress.

Larrea, J.J. (1998). La Navarre du IVe au XII siècle:peuplement et société. Paris: De Boeck Université.

Leeds, E. T. (1923). A saxon village near Sutton Courtenay, Berkshire. Archaeologia (LXXIII), 147-192.

López Quiroga, J. (2006). ¿Dónde vivían los "germanos"? En J. Morín De Pablos (Ed.), La investigación arqueológica de la época visigoda en la comunidad de Madrid (Vol. Vol. I, pp. 310-364). Madrid: Museo Arqueológico Regional.

Martín Viso, I. (2000). Poblamiento y estructuras sociales en el norte de la Península Ibérica (siglos VI-XIII). Salamanca: Ediciones Universidad Salamanca. 
Martín Viso, I. (2016a). Asentamientosy paisajes rurales en el occidente medieval. Madrid: Editorial Síntesis.

Martín Viso, I. (2016b). Comunidades locales, lugares centrales y espacios funerarios en la Extremadura del Duero altomedieval: las necrópolis de tumbas excavadas en la roca alineadas. Anuario de Estudios Medievales 46 (2), 859-898.

Milek, K. (2012). The roles of pit houses and gendered spaces on viking-age farmsteads in Iceland. Medieval Archaeology (56), 85-130.

Nissen-Jaubert, A. (1995). L'habitat rural au Danemark vers 200-1200. État des recherches. En C. Lorren y P. Périn (Eds.), L'habitat rural du Haut Moyen Age (pp. 213-222). Rouen: Musée des Antiquités de la Seine-Maritime.

Nissen-Jaubert, A. (2006). Le haut Moyen Âge. En A. Ferdière, F. Malrain, V. Matterne, P. Méniel y A. Nissen-Jaubert (Eds.), Histoire de l'agriculture en Gaule (pp. 141-197). Paris: Éditions errance.

Noël, R. (2010). À la recherche du village médiéval hier et aujourd'hui. En J.-M. Yante y A.-M. Bultot-Verleysen (Eds.), Autour du "village". Établissement humains, finages et communautés rurales entre Seine et Rhin (IVe-XIIIe siècles) (pp. 3-75). LouvainLa-Neuve: Université catolique de Louvain.

Orejas Saco, A., y Ruiz Del Árbol, M. (2013). Arqueología del paisaje: procesos sociales y territorios. En J. A. Quirós Castillo (Ed.), La materialidad de la historia. La arqueología en los inicios del siglo XXI (pp. 203-236). Madrid: Akal.

Parker Pearson, M. (1993). The powerful dead: archaeological relationships between the living and the dead. Cambridge Archaeological Journal, 3(2), 203-229.

Pastor Díaz De Garayo, E. (1996). Castilla en el tránsito de la Antigüedad al feudalismo. Poblamiento, poder politico y estructura social del Aranza al Duero (siglos VII-XI). Valladolid: Junta de Castilla y León, Consejería de Educación y Cultura.

Pecci Tenrero, H., y Ripoll López, S. (2011). El arte rupestre postpaleolítico del conjunto de Domingo García (Segovia). Espacio, Tiempo y Forma (4), 111-122.

Peytremann, É. (2003). Archéologie de l'habitat rural dans le nord de la France du IVe au XIIe siècle. Saint-Germain-en-Laye: AFAM.

Quirós Castillo, J. A. (2007). Las aldeas de los historiadores y de los arqueólogos en la Alta Edad Media en el norte peninsular. Territorio, sociedad, poder. Revista de Estudios Medievales, (2), 63-87.

Quirós Castillo, J. A. (Ed.). (2009). Archaeology of Early Medieval Villages in Europe. Vitoria-Gasteiz: Universidad del País Vasco.

Quirós Castillo, J. A. (Ed.). (2018). Treinta años de Arqueología Medieval en España. Oxford: Archaeopress.

Quirós Castillo, J. A., y Bengoetxea Rementeria, B. (2010). Arqueología III. Arqueología Postclásica. Madrid: UNED.

Quirós Castillo, J. A., y Castellanos, S. (2015). Identidad y etnicidad en Hispania. Propuestas teóricas y cultura material en los siglos V-VIII. Bilbao: Universidad del País Vasco.

Roig Buxó, J. (2009). Asentamientos rurales y poblados tardoantiguos y altomedievales en Cataluña (siglos VI al X). En J. A. Quirós Castillo (Ed.), Archaeology of Early Medieval Villages in Europe (pp. 207-251). Vitoria-Gasteiz: Universidad del País Vasco.

Roig Buxó, J. (2013). Silos, poblados e iglesias: almacenaje y rentas en época visigoda y altomedieval en Cataluña (siglos VI al XI). En A. Vigil-Escalera, G. Bianchi y J. A. Quirós Castillo (Eds.), Horrea, Barns and silos. Storage and incomes in early medieval Europe (pp. 145-170). Bilbao: Universidad del País Vasco. 
Roig Buxó, J., y Coll Conesa, J. (2011). Esquelets humans en sitges, pous i abocadors als assentaments rurals i vilatges de l'antiguitat tardana de Catalunya (segles VVIII). En I. Fernández Del Moral, J. Menchón y J. M. Vila (Eds.), Actes del IV Congrès d'Arqueologia Medieval i Moderna a Catalunya (Tarragona 2010). Vol. I (pp. 75-82). Tarragona.

Slicher Van Bath, B. H. (1963). The agrarian history of Western Europe, A.D. 500-1850. London: Edward Arnold.

Tejerizo García, C. (2012). Early medieval household archaeology in Northwest Iberia (6th-11 th centuries). Arqueologia de la arquitectura (9), 183-196.

Tejerizo García, C. (2015). Etnicidad, identidad y poder en la meseta norte durante la Edad Media: reflexiones desde la Arqueología. En J. A. Quirós Castillo y S. Castellanos (Eds.), Identidad y etnicidad en Hispania. Propuestas teóricas y cultura material en los siglos V-VIII (pp. 221-238). Bilbao: Universidad del País Vasco.

Tejerizo García, C. (2017). Arqueología de las sociedades campesinas en la cuenca del Duero durante la Primera Alta Edad Media. Bilbao: Universidad del País Vasco.

Tejerizo García, C., Carvajal Castro, Á., Marín Suárez, C., Martínez Álvarez, C., y Mansilla Hortigüela, R. (2015). La construcción histórica de los paisajes en el sector central de la cuenca del Duero. Primeros resultados de una prospección intensiva. Territorio, Sociedad y Poder (10), 39-62.

Tejerizo García, C., y Quirós Castillo, J. A. (2018). Treinta años de arqueología en el norte de la Península Ibérica. La "otra" Arqueología Medieval. En J. A. Quirós Castillo (Ed.), Treinta años de Arqueología Medieval en España (pp. 123-146). Oxford: Archaeopress.

Tipper, J. (2004). The Grubenhaus in anglo-saxon England. Yedingham: Landscape Research Centre.

Vigil-Escalera, A. (2003). Arquitectura de tierra, piedra y madera en Madrid (ss.V-IX d.C). Variables materiales, consideraciones sociales. Arqueología de la arquitectura (2), 287-291.

Vigil-Escalera, A. (2007). Granjas y aldeas altomedievales al norte de Toledo (450-800 d.C). Archivo Español de Arqueología (80), 239-284.

Vigil-Escalera, A. (2013a). Comunidad política aldeana y exclusión. Una revisión de las formas de inhumación altomedievales (ss. V-VIII d.C.). Reti Medievali Rivista, 14 $(1-42)$.

Vigil-Escalera, A. (2013b). Ver el silo medio lleno o medio vacío: la estructura arqueológica en su contexto. En A. Vigil-Escalera, G. Bianchi y J. A. Quirós Castillo (Eds.), Horrea, Barns and silos. Storage and incomes in early medieval Europe (pp. 127-145). Bilbao: Universidad del País Vasco.

Vigil-Escalera, A., Bianchi, G., y Quirós Castillo, J. A. (2013). Horrea, Barns and silos. Storage and incomes in early medieval Europe. Bilbao: Universidad del País Vasco.

Vigil-Escalera, A., Moreno García, M., Peña-Chocarro, L., Morales Muñiz, A., Llorente Rodríguez, L., Sabato, D., et al. (2014). Productive strategies and consumption patterns in the Early Medieval village of Gózquez (Madrid, Spain). Quaternary International (346), 7-19.

Vigil-Escalera, A., y Quirós Castillo, J. A. (2013). Un ensayo de interpretación del registro arqueológico. En J. A. Quirós Castillo (Ed.), Elpoblamiento rural de época visigoda en Hispania. Arqueología del campesinado en el interior peninsular. Bilbao: Universidad del País Vasco.

Vigil-Escalera, A., y Strato (2013). El registro arqueológico del campesinado del interior peninsular en época altomedieval. En J. A. Quirós Castillo (Ed.), El poblamiento 
rural de época visigoda en Hispania. Arqueología del campesinado en el interior peninsular (pp. 289-328). Bilbao: Universidad del País Vasco.

Vigil-Escalera Guirado, A. (2018). Los últimos 30 años de la arqueología de época visigoda y altomedieval. En J. A. Quirós Castillo (Ed.), Treinta años de Arqueología Medieval en España (pp. 271-294). Oxford: Archaeopress.

Vigil-Escalera Guirado, A. (2019). Meeting places, markets, and churches in the countryside between Madrid and Toledo, Central Spain (c. AD 500-900). En J. Escalona Monge, O. Vésteinsson y S. Brookes (Eds.), Polity and neighbourhood in early medieval Europe (pp. 173-202). Turnhout: Brepols.

Watteaux, M. (2003). À propos de la "naissance du village au moyen Âge": la fin d'un paradigme?. Etudes rurales, 3 (167-168), 306-318.

Wickham, C. (2005). Framing the Early Middle Ages. Oxford: Oxford University Press.

Wickham, C. (2008). Productive forces and the economic logic of the feudal mode of production. Historical Materialism (16), 3-22.

Wickham, C. (2009). The inheritance of Rome: a History of Europe from 400 to 1000. London: Penguin.

Wickham, C. (2010). L'identité villageoise entre Seine et Rhin, 500-800. En J.-M. Yante y A.-M. Bultot-Verleysen (Eds.), Autour du "village". Établissement humains, finages et communautés rurales entre Seine et Rhin (IVe-XIIIe siècles) (pp. 141-151). Louvain-La-Neuve: Université catolique de Louvain.

Wolf, E. R. (1966). Peasants. New Jersey: Prentice-Hall.

Zadora-Rio, E. (1995). Le village des historiens et le village des archeologues. En E. Mornet (Ed.), Campagnes médiévales: l'homme et son espace. Paris: Publications de la Sorbonne.

\section{Notas}

1 Este trabajo ha sido realizado en el marco del Proyecto "Agencia campesina y complejidad sociopolítica en el noroeste de la Península Ibérica en época medieval" (Ministerio de Economía, Industria y Competitividad, AEI/FEDER UE HUM2016-76094-C4-2-R), del Grupo de Investigación en Arqueología Medieval, Patrimonialización y Paisajes Culturales / ErdiArokoArkeologia, Ondaregintza eta KulturPaisaiakIkerketaTaldea(Gobierno Vasco, IT1193-19) y del Grupo de Estudios Rurales (Unidad Asociada UPV/EHU-CSIC). Quedo especialmente agradecido a Eduardo Daflon por sus ideas respecto a los temas tratados en este trabajo y a la evaluación externa por sus comentarios y sugerencias.

2 El autor es Investigador postdoctoral del Grupo de Investigación en Patrimonio y Paisajes Culturales.

3 Si bien existen excepciones, como ocurre con algunos textos hagiográficos, como veremos más adelante.

4 Si bien no existen, como en la Comunidad de Madrid, aldeas enteras excavadas, podemos llegar a este cálculo a través de la estimación entre la superficie excavada y la extensión calculada para el yacimiento a través de los trabajos de prospección.

5 Lo cual no excluye la existencia de aldeas nucleadas como ocurre en el caso de La Dehesa del Cañal (Pelayos, Salamanca) (Fabián, Santonja, Fernández, y Benet, 1985).

6 Y a muchos otros cementerios de los cuales solo tenemos una información parcial de su verdadera extensión

7 Vita Sancti Aemiliani (VSA), XII.26 and XXI.28, ed. Andrew Fear (Liverpool, 1997) pp. 33, 35 . 